\title{
Assessing Mothers' Automatic Affective and Discipline Reactions to Child Behavior in Relation to Child Abuse Risk: A Dual-Processing Investigation
}

\author{
Christina M. Rodriguez' (D), Paul J. Silvia² ${ }^{\text {, Shawna J. Lee }}{ }^{3}$, and \\ Andrew Grogan-Kaylor ${ }^{3}$
}

\begin{abstract}
Given the scope and adverse clinical consequences of child abuse, assessment of salient etiological factors can lend critical insights needed for abuse prevention. Increasingly, dual-processing models have been applied to aggression, which postulate that parallel automatic and conscious processes can evoke aggressive behavior, implicating both affective and cognitive elements in both routes. Using two samples of mothers $(n=110$ and $n=195)$, the current investigation considered evidence of the reliability and convergent, concurrent, and construct validity of the new Automatic Parent Emotion Analog Response task relevant to parent-child aggression, contrasted with a self-reported conscious processing measure. Findings provide evidence that affective reactions of both anger and worry relate to child abuse risk and inclination to respond aggressively, and demonstrate how mothers' automatic reactions relate to both perceived child misbehavior and child dangerous behavior. Current results lend psychometric support for automatic processing in parent-child aggression consistent with other dual-processing theories of aggression.
\end{abstract}

\section{Keywords}

child maltreatment, child abuse potential, physical discipline, dual processing, social-information processing theory, automatic processing, implicit measurement

Distinct forms of child maltreatment are officially recognized by child protective services, including intentional actions that incur physical injury - namely physical abuse (U.S. Department of Health \& Human Services, 2020). About 678,000 children are substantiated for maltreatment annually (U.S. Department of Health \& Human Services, 2020), although research tracking cases across time suggests a cumulative estimate that $12.5 \%$ of children across the United States will be substantiated for child maltreatment at some point before age 18 years (Wildeman et al., 2014). Nonetheless, robust evidence reveals the extent to which official substantiated reports vastly underestimate the scope of child maltreatment (Meinck et al., 2016; Sedlak et al., 2010; Stoltenborgh et al., 2015). Given the underestimates derived from official records, alternative methods directly seek parent self-report of their child maltreatment, although social desirability concerns markedly inhibit parents' candor in such reports (e.g., Chan, 2012; Meinck et al., 2016; Widom et al., 2015).

Consequently, researchers often employ an indirect approach to collect data from parents that strives to predict their child abuse risk, a constellation of parenting beliefs and behaviors that characterizes those who physically abuse their children (Bavolek \& Keene, 2001; Chaffin \& Valle, 2003; Milner, 1994). Predicting child abuse risk is essential for abuse prevention efforts (Chaffin et al., 2011; Duffy et al., 2015). For example, physical discipline use is a potent predictor of physical child abuse (Gershoff \& GroganKaylor, 2016) because when parents escalate the frequency or intensity of physical discipline, physical abuse becomes increasingly likely (Afifi et al., 2017; Durrant et al., 2009; Zolotor et al., 2008). As a result, physical discipline is often construed as quantitatively different from physical abuse, wherein physical discipline and physical abuse are endpoints along a gradually intensifying parent-child

\footnotetext{
'University of Alabama at Birmingham, Birmingham, AL, USA

2University of North Carolina Greensboro, Greensboro, NC, USA

${ }^{3}$ University of Michigan, Ann Arbor, MI, USA

Corresponding Author:

Christina M. Rodriguez, Department of Psychology, University of Alabama at Birmingham, 1720 2nd Avenue South, Birmingham, AL 35294, USA.

Email: cmrpsych@uab.edu
} 
aggression continuum (Gershoff, 2010; Gonzalez et al., 2008; Rodriguez, 2010). Despite underreporting, parents' self-reported greater use of parent-child aggression is often utilized as one indicator of parents' child abuse risk. Child abuse risk, parent-child aggression use, and physical abuse are all established contributors to an array of short-term and long-term clinical problems (Coley et al., 2014; Font \& Berger, 2015; Gershoff \& Grogan-Kaylor, 2016; Maneta et al., 2017; Rodriguez, 2006; Sousa et al., 2018), underscoring the need for advances in assessment that elucidate the etiological underpinnings of parent-child aggression.

To conceptualize the complex etiological factors leading to parent-child aggression, social-information processing theory has been applied to parent-child aggression, emphasizing sociocognitive processes (Milner, 2000; Rodriguez et al., 2019, 2020). According to this theory, parents maintain preexisting schemas (e.g., parenting-related beliefs) before a discipline situation even arises. Then, when faced with parent-child conflict, parents undergo a series of cognitive processes wherein they may misperceive and interpret the situation negatively before selecting parent-child aggression as a discipline response. Empirical support for this model provides evidence that one social-information processing preexisting schema-parents' approval of parent-child aggression as a discipline option-is related to greater child abuse risk (Bi \& Keller, 2019; Rodriguez et al., 2011; Smith Slep \& O'Leary, 2007). Moreover, parents' negative attributions about the intentions behind children's misbehavior (considered a social-information processing interpretation) has been a consistent predictor of child abuse risk (Azar et al., 2016; Beckerman et al., 2018; Camilo et al., 2020; Haskett et al., 2006; Rodriguez, 2018). Notably, the propensity to react with parent-child aggression may not be limited to only perceived child misbehavior but also to perceived dangerous behavior (Bower-Russa et al., 2001; Crouch et al., 2017; Russa et al., 2014), although considerably less empirical inquiry has expressly differentiated parent-child aggression reactions to these two types of child behavior.

The emphasis on cognitive processes in much of this research is conspicuous. Such work often neglects the role of emotion despite the long-standing recognition that both cognitive and affective systems contribute to aggressive behavior in general (Buss, 1961), particularly anger (Averill, 1982). Indeed, the need to expressly integrate negative affect into social-information processing models has been postulated for other forms of aggression (e.g., Lemerise \& Arsenio, 2000). Anger has been identified as an important independent predictor of child abuse risk (Hien et al., 2010; Smith Slep \& O'Leary, 2007; Stith et al., 2009), as an element contributing to abuse risk within social-information processing models (Rodriguez, 2018; Rodriguez \& Richardson, 2007), and as an intervention target in maltreatment prevention programs (Altafim \& Linhares, 2016;
Sanders et al., 2004). Although the emotion of anger has received the bulk of attention when emotion is examined in the study of parent-child aggression, research rarely examines parents' experience of anxiety. In that limited work, parental anxiety was identified as a predictor of physical child abuse (Stith et al., 2009) and worry for their children was significantly associated with severe discipline in a large sample of mothers' of kindergarteners (Pinderhughes et al., 2000). Thus, the current investigation explicitly considered both parental anger and parental worry as potential negative affective elements parents may experience that contributes to their child abuse risk.

The social-information processing model speculates that negative affect could influence cognitive processing, but further acknowledges that parents likely engage in automatic processing during some episodes of parent-child aggression (Milner, 2000). Historically, premeditated, instrumental aggression was construed as conscious and deliberative, and expressly distinguished from impulsive, reactive, or hostile aggression that was more tied to emotion (Buss, 1961). Since then, debate arose regarding these potentially artificial dichotomies because motives for aggression are often mixed (Bushman \& Anderson, 2001) heralding a shift toward more dual-processing models of aggressive behavior (e.g., Orobio de Castro, 2004). In dualprocessing models, the aggressor may act because of reflective, conscious processing once an event is perceived as aversive - a pro-active aggressive approach - or the aggressor may act via a more automatic, reactive, impulsive route (Orobio de Castro, 2004). Essentially, the differentiation between automatic and conscious processing lies not in emotion but in the speed and efficiency with which behavioral enactment ensues (Bluemke \& Teige-Mocigemba, 2015). Parents may experience an emotional reaction after perceiving child behavior in either conscious or automatic processing modes but when automatic processing occurs, parent-child aggression immediately follows without cognitive reflection after perceiving an aversive child behavior and experiencing the emotion. Nonetheless, research in the field of child abuse risk has concentrated almost exclusively on conscious, controlled processes.

This oversight in part reflects the field's methodological reliance on explicit, direct assessment of child abuse risk and parent-child aggression use (e.g., Bavolek \& Keene, 2001; Milner, 1994; Straus et al., 1998). However, as noted earlier, direct reports from parents regarding their parentchild aggression use are subject to underreporting and response bias (Chan, 2012; Meinck et al., 2016). Alternatives to explicit assessment can utilize indirect assessment approaches like analog tasks that are less susceptible to participant misrepresentation, adopting implicit strategies occurring outside conscious awareness (Camilo et al., 2016; Fazio \& Olson, 2003), or via behavioral simulations. With these indirect, analog approaches, respondents are not 
expressly aware of the purpose of the task or how scores are calculated or interpreted, thereby minimizing participant response biases. If a respondent becomes aware of the task's intent, or has sufficient time to manipulate their response, the potential for response distortion escalates. Thus, more transparent indirect analog tasks yield higher correlations with comparable self-report measures relative to the lower correlations observed when using more ambiguous analog methods.

Efforts to design implicit tasks relevant to child abuse risk factors have utilized speeded word-sorting tasks like go-no-go paradigms to assess implicit attitudes approving of parent-child aggression (Sturge-Apple et al., 2015) or Implicit Association Task paradigms to assess negative child behavior attributions (Rabbit \& Rodriguez, 2019). Alternatively, other implicit approaches have utilized subliminal priming to influence parents' negative perceptions of children that influence high-risk parents' hostility ratings toward children (Farc et al., 2008). Eyetracking has been utilized to identify implicit negative child behavior attributions in relation to child abuse risk (Rodriguez et al., 2012). Alternatively, behavior simulations have been utilized wherein parents at higher child abuse risk provide more aversive sound blasts for fictional opponents (Crouch et al., 2012), demonstrate lower frustration tolerance via quicker termination of simulated aversive parent-child situations (McElroy \& Rodriguez, 2008; Rodriguez et al., 2015), or exhibit stronger hand grip strength after exposure to child affect (Compier-de Block et al., 2015).

Although implicit approaches may capture unconscious processing, current analog methods do not expressly target automatic processing of stimuli. One example of a speeded analog task designed to acquire automatic negative child attributions displayed line drawings of children engaged in bad or clumsy behavior to parents for 4,000 ms and immediately asked parents to provide responses to eight dichotomous questions on attributions each presented at 3,500 ms each (Beckerman et al., 2018). This automatic processing task for attributions was significantly related to parentreported parent-child aggression use (Beckerman et al., 2018). This rapid-delivery approach appears to simulate the automatic processing in dual-processing models that may transpire in parents' immediate reactions on perceiving child behavior.

\section{Current Study}

Therefore, the current investigation aimed to evaluate the psychometric qualities of a new analog task of mothers' automatic processing of child-relevant stimuli, simulating their encoding of child behavior, in relation to parents' child abuse risk. To replicate findings, two separate samples of mothers reported their emotions as well as discipline intentions on the new automatic processing analog task and provided comparable responses using a more traditional consciously processed self-report measure of their emotions and discipline intentions for misbehavior. After evaluating the reliability of the new analog task, several forms of validity evidence were investigated. Convergent validity was studied by considering whether mothers' automatic emotional responses of anger and worry to rapidly presented stimuli of child misbehavior or dangerous behavior would be significantly related to child abuse risk and parentreported use of parent-child aggression. Using longitudinal data from the first sample, we further probed whether these automatic emotional reactions or physical discipline selections related to previous assessments of child abuse risk or parent-child aggression use. Additionally, concurrent validity was appraised focusing on two social-information processing factors: attitudes approving of parent-child aggression use, which represent a social-information processing preexisting schema, and negative child intent attributions, which represent a social-information processing interpretation. Finally, we evaluated the construct validity of the new analog task by weighing evidence of convergent versus discriminant validity with the consciously processed self-report measure. After first considering bivariate associations from both study samples, a multitrait-multimethod matrix (MTMM) was examined via confirmatory factor analysis (CFA) with the samples combined to establish whether automatic and conscious processing were related but distinct approaches.

\section{Method}

\section{Participants and Procedures: Sample I}

The first sample was drawn from the Following First Families ("Triple-F") study (see Rodriguez et al., 2016, 2019, 2020), a prospective longitudinal study conducted in a large southeastern U.S. city. Participants were recruited via flyers distributed at local hospital ob/gyn clinics/childbirth classes for a three-wave study. The study oversampled families at-risk for abuse, enrolling mothers from public subsidized health centers who reflected one or more sociodemographic risks (i.e., $\leq 150 \%$ of the federal poverty line, receipt of federal assistance, $\leq$ high school education, single parenthood, $\leq$ age 18 years). Interested mothers contacted the lab to schedule in-person sessions. The university Institutional Review Board granted approval for each phase of the study.

In the Triple-F study, 203 first-time mothers were enrolled and assessed (Time 1) and reassessed when their infants were 6 months old (Time 2). The waves of interest for the current investigation involve assessments of mothers' child abuse risk and parent-child aggression use at Time 3 and beyond. Time 3 involved 180 mothers ( $90 \%$ of those still eligible) when their children were 18 months old 
Table I. Demographic Characteristics for Sample I and Sample 2.

\begin{tabular}{|c|c|c|c|c|}
\hline & \multicolumn{3}{|c|}{ Triple-F study Sample I } & \multirow[t]{2}{*}{ Prolific Sample 2} \\
\hline & Time 3 & Time 4 & Time 5 & \\
\hline & $M(S D)$ or $\%$ & $M(S D)$ or $\%$ & $M(S D)$ or $\%$ & $M(S D)$ or $\%$ \\
\hline Age (years) & $28.36(5.37)$ & 31.08 (5.59) & $33.03(5.52)$ & 32.50 (5.89) \\
\hline \multicolumn{5}{|l|}{ Race } \\
\hline White & 57.4 & 58.6 & 59.1 & 53.3 \\
\hline African American & 39.8 & 40.2 & 38.2 & 45.6 \\
\hline Asian & 1.9 & I.I & 1.8 & 0 \\
\hline Native American/Alaskan & 0.9 & 0 & 0.9 & 1.0 \\
\hline \multicolumn{5}{|l|}{ Ethnicity } \\
\hline Not Hispanic/Latina & 95.4 & 94.3 & 95.5 & 96.9 \\
\hline Hispanic/Latina & 4.6 & 5.7 & 4.5 & 3.1 \\
\hline \multicolumn{5}{|l|}{ Spouse/partner } \\
\hline Yes & 86.1 & 87.4 & 83.6 & 81 \\
\hline No & 13.9 & 12.6 & 16.4 & 19 \\
\hline \multicolumn{5}{|l|}{ Educational level } \\
\hline$\leq$ High school & 16.7 & 19.5 & 18.2 & 11.3 \\
\hline Some college & 24.1 & 19.5 & 19.1 & 28.7 \\
\hline College degree & 27.8 & 26.4 & 27.3 & 30.8 \\
\hline$>$ College degree & 31.5 & 31.5 & 35.5 & 29.2 \\
\hline Median household income & $\$ 40,000-\$ 49,999$ & $\$ 50,000-\$ 59,999$ & $\$ 50,000-\$ 59,999$ & $\$ 50,000-\$ 59,999$ \\
\hline \multicolumn{5}{|l|}{ Receipt public assistance } \\
\hline Yes & $29.6 \%$ & $28.7 \%$ & $26.4 \%$ & $31.8 \%$ \\
\hline No & $70.4 \%$ & $71.3 \%$ & $73.6 \%$ & $68.2 \%$ \\
\hline
\end{tabular}

Note. Triple-F Study Time 3 = child age 18 months, Time $4=$ child age 4 to $41 / 2$ years, Time $5=$ child age 5 to $61 / 2$ years. Triple-F Study demographics reported are those provided at each time point.

( \pm 3 weeks). After the study closed, Triple-F was extended for Time 4, locating and assessing 119 mothers when their children had turned 4 years olds ( 4 to $4 \frac{1}{2}$ years). For all of these in-person sessions, measures were administered electronically on laptop computers with headphones.

To test the new automatic processing analog task, mothers were again located and invited to participate in an online study (via Qualtrics) for Time 5 when their children were between 5 and $6 \frac{1}{2}$ years old. Power analyses indicated that a minimum sample size of 85 would be required for power at .80 and $\alpha$ at .05. In Time 5, 110 mothers participated. Sample 1 demographics by time point appear on the left side of Table 1 .

\section{Participants and Procedures: Sample 2}

The second sample was gathered using the same online (Qualtrics) survey, administered via Prolific, an online survey research and data collection company used in psychological research (Palan \& Schitter, 2018). To be eligible, participants had to be age 18 years or older, reside in the United States, and be parents of at least one child age 8 years or younger. Per Prolific's study procedures, the research team set target enrollment numbers and sought to recruit a balance of African American and White mothers to be similar in racial composition to Sample 1. Based on the study recruitment parameters, Prolific sent an e-mail with the Qualtrics survey link to eligible participants. Thus, unlike mothers in the Triple-F study sample, these 195 mothers responded anonymously. Sample 2 demographics by time point appear on the right side of Table 1. Prolific provided incentives $(\$ 7.00)$ to respondents who were eligible and completed the survey. These data were de-identified thus the university institutional review board deemed this study sample exempt from oversight.

\section{Measures}

Automatic Versus Conscious Processing for Both Samples

Automatic Parent Emotion Analog Response (APEAR). The APEAR task was designed to assess automatic affective reactions and discipline intentions to stimuli of child behavior that appear rapidly. Three categories, each with 16 photos, were then randomly presented: Bad (e.g., fighting, temper tantrum, stealing-involving potential willful misbehavior), Danger (e.g., playing with electrical socket, knives, iron-involving potential child injury), and Good (e.g., reading, vacuuming, brushing teeth-involving 


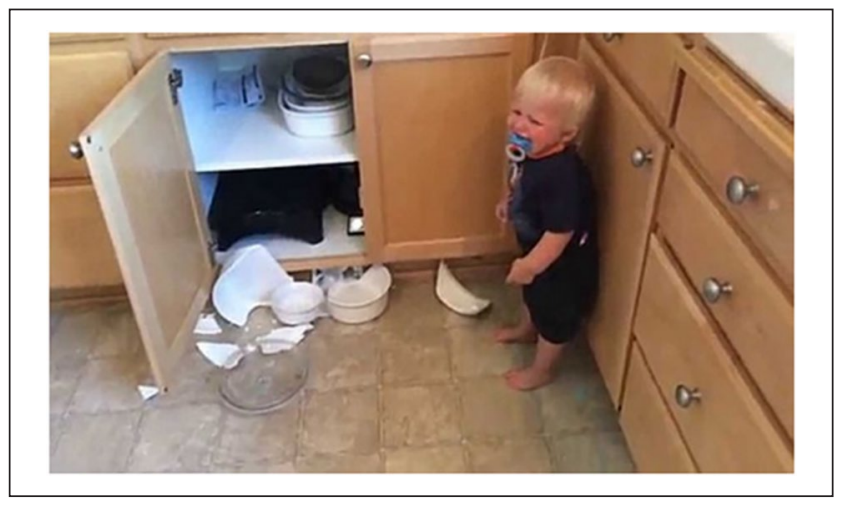

Figure I. Sample image from APEAR practice phase. Note. APEAR = Automatic Parent Emotion Analog Response.

neutral or helpful behavior). Images were obtained from publicly available images online, typically focused on a single child, and 10 research lab assistants sorted the images into these three categories. Each category was gender-balanced, and children of color were depicted in $31.25 \%$ of the images in both the Bad and Danger category and $40.6 \%$ in the Good category. Each image was sized at $550 \times 325$ pixels. See Figure 1 for sample image from the practice phase.

To determine timing of the images and follow-up questions, we began with the timing successfully utilized by Beckerman et al. (2018) for automatic attributions as a starting point (they presented drawings for $4000 \mathrm{~ms}$ and sought eight yes/no attributions responses, each within $3500 \mathrm{~ms}$ ). We conducted pilot tests within the lab and informally with a half-dozen parents outside the lab, coming to the following conclusions: (a) by consensus, $4000 \mathrm{~ms}$ was indeed needed to process the details of the initial image, comparable to Beckerman et al.; (b) all testers believed $3500 \mathrm{~ms}$ was too long for an immediate emotional reaction (anger, anxiety) thus, we reduced to $3000 \mathrm{~ms}$, which was deemed sufficient; and (c) given the need to physically navigate with a computer mouse among five options for the behavioral intention, using an iterative process, we determined that the practice phase taught respondents the location of the options and by consensus, determined $5000 \mathrm{~ms}$ would be sufficient.

At the start of APEAR, parents received the initial instruction:

You are about to see some pictures of children doing different things shown very quickly. Because this is timed, do not take a break during this task. Look at each picture and imagine this was your most difficult child. Then answer the question about whether that behavior would make you angry or worried and then what you would do. You will need to answer as fast as possible so give your first, most natural answer. Let's practice some now.

Each image was presented for $4000 \mathrm{~ms}$, immediately followed by three questions: (a) "Would this make you angry?" (b) "Would you worry about your child?" and (c) "What would you do?" To attain immediate affective reactions, rather than using a rating scale, the first two emotion questions were posed "yes/no" for 3,000 ms. Similarly, to acquire quick responses for the behavioral intention question, parents were given word choices that could apply to all three categories in the same order for 5,000 ms: Reward, Nothing/Ignore, Distract, Punish, Hit/Spank. Before the main trials, the practice phase presented eight images to train the participants in rapidly responding to these questions: The first half of the practice images were presented for an additional one second for the first two questions and an additional two seconds for the third question; the second half of the practice images matched the speed of the main trials. Failure to respond within the prescribed time limit on these questions prompted an alert to select a response immediately in order to proceed with the task.

Responses on the APEAR yielded total scores for the stimuli of primary interest: Bad and Danger. Anger total count scores reflect the number of times participants reported anger to the images of children engaged in misbehavior or dangerous behavior; Worry total count scores reflect the number of times participants reported worry for these images; and Hit/Spank, Punish, and Distract total count scores reflect the number of times either of these behavioral intention responses was selected.

Plotkin Child Vignettes (PCV; Azar et al., 2016; Haskett et al., 2006; Plotkin, 1983). An adapted version of the PCV was administered to serve as an explicit report of conscious processing. This measure includes 18 brief vignettes that have previously been used to assess parents' negative child intent attributions and punishment intentions in response to child misbehavior. Parents are asked to imagine the situation in the vignette occurred with their child and to indicate how much they thought the child acted intentionally to annoy the parent on a 9-point scale, from 1 (did not mean to annoy me at all) to 9 (the only reason the child did this was to annoy me), with higher total scores summed across all vignettes indicative of more negative child attributions. Although the PCV typically follows this attribution question with a query on their likelihood to punish, also on a 9-point scale, the PCV was adapted to more closely mirror the APEAR. Thus, following the attribution question, instead of the punish question, parents were asked to report how angry or frustrated they would feel from 1 (not angry or frustrated at all) to 9 (very angry or frustrated) and to report how worried they would be for their child from 1 (not worried about my child at all) to 9 (very worried about my child). Last, parents were asked to report how they would react to their child's misbehavior with the following choices: ignore, punish, hit/spank, talk. Total scores were computed summing responses across the 
18 vignettes for total Attribution, Anger, and Worry scores, and frequency counts for how often parents selected Hit/ Spank and Punish. Previous research has demonstrated that abusive mothers are more inclined toward negative child attributions and punishment than nonabusive parents on the PCV, with acceptable internal consistency (Haskett et al., 2006).

\section{Cross-Sectional Comparison Measures in Both Samples}

Adult Adolescent Parenting Inventory-2 (AAPI-2; Bavolek \& Keene, 200I). The AAPI-2 is a self-report measure of parenting beliefs intended to assess child abuse risk, with items selected that distinguish maltreating versus nonmaltreating parents. Parents indicate their level of agreement on 40 items using a 5-point Likert-type scale from 1 (strongly disagree) to 5 (strongly agree), with a total score summed across items wherein higher scores were oriented to indicate higher child abuse risk. A psychometric evaluation of the AAPI-2 reported good reliability and validity (Conners et al., 2006).

Parent-Child Conflict Tactics Scale (CTSPC; Straus et al, 1998). The CTSPC was developed using a nationally representative sample, asking parents to estimate the frequency with which they have used 22 potential behaviors in response to conflicts with children. Although four items involve nonviolent discipline approaches, and five items consist of psychological aggression, of interest for the current investigation were parent reports of 13 physical tactics that vary widely in severity, contributing to a Physical Assault subscale. For each tactic, parents indicate whether they have engaged in the behavior with the following response categories: $0=$ never happened; $1=$ once; $2=$ twice; $3=3$ to 5 times; $4=6$ to 10 times; $5=11$ to 20 times; $6=$ more than 20 times. The CTSPC provides summary scores of low-frequency count data weighted depending on participant responses, with selections of 0,1 , and 2 corresponding to scores of 0,1 , and 2 , respectively; responses of 3 to 5 times receive a weight of 4 (the midpoint); selections of 6 to 10 times receive the midpoint score of 8 ; selection of 11 to 20 times is weighted with a score of 15; and selecting 20 or more times is weighted with a score of 25. The test authors report evidence of construct and discriminant validity (Straus et al., 1998).

Attitudes Toward Spanking (ATS; Holden, 200I). The ATS scale is a self-report measure of approval of using parent-child aggression. This measure presents 10 items on a 7-point scale on which respondents report their level of agreement, from 1 (strongly disagree) to 7 (strongly agree), with items summed for a total score with higher values indicative of greater approval of parent-child aggression. Prior evidence supports reliability (Holden, 2001) and scores predict mothers' actual parent-child aggression use (Ateah \& Durrant, 2005).
Longitudinal Comparison Measures for Sample I. The AAPI-2 abuse risk measure and CTSPC parent-child aggression use measure were also administered at Time 3 and Time 4 to the Triple-F sample of mothers. Two additional measures of child abuse risk were also administered at these time points, the CAPI and ReACCT, described below.

Child Abuse Potential Inventory (CAPI; Milner, 1986). The CAPI is a measure designed to screen for physical child abuse risk, with items measuring rigidity, distress, and interpersonal problems observed in substantiated abuse perpetrators. Unlike the AAPI-2, the CAPI largely does not expressly inquire about parenting or discipline. Parents respond to 160 Agree/Disagree statements, although only 77 items are variably weighted to contribute to the Abuse Scale score, with higher scores indicative of elevated child abuse risk. Studies demonstrate strong psychometric properties for the Abuse Scale (Milner, 1986, 1994), including predictive validity, correctly classifying $89.2 \%$ of confirmed child abusers and 99\% of controls (Milner, 1994).

Response Analog to Child Compliance Task (ReACCT; Rodriguez, 2016). ReACCT is a computer-simulated analog of a common parent-child challenge where parents are instructed that they are running late one morning and need to get their child to preschool. In 12 sequential scenes, parents see instructions they presumably provided to their child and the child is then either reported to be compliant or noncompliant. A visual and audible clock ticks throughout the simulation to indicate how delayed the parent and child are in leaving home to elicit time urgency. Parents can remain "stuck" in a scene if the child continues to be noncompliant, whereas they can see a game bonus (50 cents) for each time they secure quick compliance. In response to the child, parents have 16 possible responses to the child's behavior in the scene. Scores are positively or negatively weighted depending on the parent's adaptive (e.g., praise) versus maladaptive (e.g., aggressive) response to the child's actions. ReACCT presents 12 instances of child noncompliance, and 8 instances of child compliance, with higher scores indicating greater abuse risk. The ReACCT Noncompliance scores were the focus of this investigation, demonstrating convergent validity with child abuse risk and abusive physical discipline tactics (Rodriguez, 2016).

\section{Analytic Plan}

Analyses involve the measures listed above that were administered to both samples (with the exception of the longitudinal measures) with no data exclusions or manipulations. Preliminary analyses utilized SPSS 27 to provide descriptive statistics and to report on sample demographic differences using chi-square or $t$-tests. Regarding reliability of the APEAR scores of primary interest, Anger, Worry, and Hit/Spank for 
both Bad and Danger stimuli each involve 16 responses. Although we provide the customary Cronbach's alpha coefficients for these scores, we also computed the expected a posteriori reliability using Rasch models using TAM (Robitzsch et al., 2020) for the dichotomous emotion scores. Expected a posteriori reliability is suitable for binary yes/no data and interpreted on the same scale as coefficient alpha.

In terms of validity evidence, bivariate correlations for convergent validity are presented for mothers' affective responses and discipline selections on the APEAR Bad and Danger stimuli with the concurrent assessment of child abuse risk (AAPI-2) and self-reported physical discipline use (CTSPC). We also evaluated whether these findings were replicated by providing similar bivariate correlations for these APEAR scores with the earlier assessment of mothers' child abuse risk (AAPI-2, CAPI Abuse Scale, ReACCT) as well as parent-child aggression use (CTSPC). To demonstrate concurrent validity, bivariate correlations between APEAR responses and parent-child aggression approval attitudes (ATS) and negative child attributions (PCV) are presented.

Finally, we examined APEAR construct validity by considering evidence of convergent versus discriminant validity between automatic and conscious processing of misbehavior. First, bivariate correlations between selfreports on the vignettes (PCV) and the APEAR scores were evaluated for each sample separately. We also conducted simultaneous multiple regression analyses to ascertain whether APEAR Hit/Spank scores, when tested at the same time as the comparable vignette scores (PCV Hit/Spank), independently predicted child abuse risk (AAPI-2) or selfreported parent-child aggression use (CTSPC). Then, combining both study samples, we considered the MTMM (Campbell \& Fiske, 1959) for the two methods (automatic and conscious) by the three constructs of most interest, Anger, Worry, and Hit/Spank, first presented in a conventional correlation table. We then tested the MTMM using CFA, which separated effects of methods and traits and allowed us to confirm that automatic and conscious processes were distinct. Model fit was judged to be good (Kline, 2011) if values exceeded .95 for comparative fit index and were below .08 for root mean square error of approximation and standardized root mean square residual.

\section{Results}

\section{Preliminary Analyses}

Samples did not significantly differ in terms of racial or ethnic composition, partnership status, receipt of public assistance, maternal age, household annual income, or maternal educational level (all $p>.25$ ). Descriptive statistics and internal consistencies for APEAR Bad and Danger stimuli and comparison measures appear in Table 3 for both samples. Bivariate correlations within the APEAR Bad and Danger stimuli separately are presented in Table 3 for Sample 1 and Table 4 for Sample 2. The pattern of findings for both samples indicate that if the mother experienced anger in response to images of the child engaging in misbehavior or dangerous behavior, she was more inclined to select a hit/spank or punish response but less inclined to select distraction. Anger and worry affective reactions were significantly positively associated with each other only for misbehavior, not dangerous behavior, and experiencing worry was positively associated with selecting a hit/spank response only for misbehavior, not dangerous behavior. Dangerous child behavior appeared more likely to elicit distraction, rather than hit/spank or punish responses.

\section{APEAR Reliability}

Cronbach's alphas for both samples appear in Table 2 . Using Rasch models to compute the expected a posteriori reliability for the dichotomous APEAR Bad stimuli Anger and Worry scores, values were .78 and .85 , respectively, and for Danger stimuli, Anger and Worry expected a posteriori reliability values were .87 and .62 , respectively for Sample 1. For Sample 2, expected a posteriori reliability for the APEAR Bad stimuli Anger and Worry was .76 and .81, respectively, and for Danger stimuli, Anger and Worry expected a posteriori reliability was .88 and .67 , respectively. In both samples, alphas indicate acceptable internal consistency for APEAR Bad and APEAR Danger stimuli Anger, Worry, and Hit/Spank counts. Because the discipline intention counts on both the APEAR and the PCV function similar to multiple choice items, internal consistency was low, for instance, for Bad Distract or Punish because those choices are infrequently selected; in contrast, those options were more frequently selected for Danger stimuli, resulting in higher internal consistencies for those count scores.

\section{Convergent Validity Evidence}

Tables 3 and 4 depict correlations of the APEAR Bad and Danger stimuli with measures of child abuse risk (AAPI-2 Total) and self-reports of parent-child aggression use (CTSPC Physical Assault) for the two samples. For the APEAR stimuli depicting misbehavior, higher child abuse risk on the AAPI-2 abuse risk measure was significantly associated with greater anger and worry and selection of hit/ spank responses and lower likelihood of selecting distraction for both samples. For the APEAR stimuli depicting dangerous behavior, mothers with higher AAPI-2 Total abuse risk scores reported higher anger and a tendency to select hit/spank and punish options, but significantly lower worry or likelihood of selecting distraction. In the first sample, none of the APEAR scores were significantly related with mothers' self-report of parent-child aggression use on 
Table 2. Means, Standard Deviations, and Internal Consistencies for Samples I and 2.

\begin{tabular}{|c|c|c|c|c|c|c|}
\hline & \multicolumn{3}{|c|}{ Triple-F study Sample I } & \multicolumn{3}{|c|}{ Prolific Sample 2} \\
\hline & $M(S D)$ & Range & $\alpha$ & $M(S D)$ & Range & $\alpha$ \\
\hline \multicolumn{7}{|l|}{ Time 5} \\
\hline APEAR Bad Anger & $8.55(3.32)$ & $0-15$ & .77 & $9.20(3.33)$ & $0-16$ & .76 \\
\hline APEAR Bad Worry & $7.19(3.83)$ & $2-16$ & .85 & $8.14(3.64)$ & $2-16$ & .82 \\
\hline APEAR Bad Hit/Spank & $0.89(1.84)$ & $0-12$ & .81 & $0.97(1.66)$ & $0-7$ & .72 \\
\hline APEAR Bad Distract & $3.44(2.05)$ & $0-9$ & .46 & $3.57(2.77)$ & $0-13$ & .70 \\
\hline APEAR Bad Punish & $8.41(2.38)$ & $2-16$ & .53 & $7.21(3.01)$ & $0-14$ & .69 \\
\hline APEAR Danger Anger & $4.62(4.93)$ & $0-16$ & .93 & $6.57(4.85)$ & $0-16$ & .91 \\
\hline APEAR Danger Worry & $14.43(2.17)$ & $5-16$ & .78 & $14.00(2.46)$ & $4-16$ & .78 \\
\hline APEAR Danger Hit/Spank & $1.03(2.30)$ & $0-13$ & .88 & $1.28(2.53)$ & $0-14$ & .87 \\
\hline APEAR Danger Distract & $10.78(4.27)$ & $0-16$ & .88 & $10.39(4.39)$ & $0-16$ & .88 \\
\hline APEAR Danger Punish & $3.58(3.23)$ & $0-14$ & .81 & $3.04(2.97)$ & $0-15$ & .80 \\
\hline PCV Anger & $52.04(21.93)$ & $18-125$ & .92 & $64.50(23.53)$ & $21-127$ & .91 \\
\hline PCV Worry & $55.5 \mathrm{I}(22.2 \mathrm{I})$ & $18-119$ & .87 & $76.44(27.70)$ & $24-162$ & .90 \\
\hline PCV Hit/Spank & $0.49(0.94)$ & $0-4$ & .54 & $0.94(1.82)$ & $0-10$ & .79 \\
\hline PCV Punish & $2.12(1.4 I)$ & $0-6$ & .42 & $2.47(1.80)$ & $0-15$ & .61 \\
\hline PCV Attribution & $36.21(16.35)$ & $18-104$ & .87 & $47.58(23.01)$ & $18-133$ & .92 \\
\hline AAPI-2 Total & $94.72(21.27)$ & $51-160$ & .93 & $96.68(24.11)$ & $48-160$ & .93 \\
\hline CTSPC Physical Assault ${ }^{a}$ & $7.08(9.5 \mathrm{I})$ & $0-55$ & & $12.20(2 \mid .04)$ & $0-112$ & \\
\hline ATS Total & $37.98(14.54)$ & $10-67$ & .91 & $35.58(17.24)$ & $10-69$ & .95 \\
\hline \multicolumn{7}{|l|}{ Time 4} \\
\hline AAPI-2 Total & $88.98(21.45)$ & $51-130$ & .90 & & & \\
\hline CTSPC Physical Assault ${ }^{\mathrm{a}}$ & 9.78 (13.74) & $0-79$ & & & & \\
\hline ReACCT Noncompliance & $-5.63(10.83)$ & $-18-32$ & .80 & & & \\
\hline CAPI Abuse Scale ${ }^{b}$ & $78.43(73.06)$ & $2-376$ & & & & \\
\hline \multicolumn{7}{|l|}{ Time 3} \\
\hline AAPI-2 Total & $95.81(21.84)$ & $53-156$ & .91 & & & \\
\hline CTSPC Physical Assault ${ }^{\mathrm{a}}$ & $6.87(10.55)$ & $0-51$ & & & & \\
\hline ReACCT Noncompliance & $-2.29(12.46)$ & $-20-42$ & .81 & & & \\
\hline CAPI Abuse Scale ${ }^{b}$ & $84.92(76.89)$ & $1-362$ & & & & \\
\hline
\end{tabular}

Note. APEAR = Automatic Parent Emotion Analog Response task; PCV = Plotkin Child Vignettes; AAPI-2 = Adult Adolescent Parenting Inventory-2; CTSPC Physical = Parent-Child Conflict Tactics Scale; ReACCT Noncompliance $=$ Response Analog to Child Compliance Task, Noncompliance Scale; CAPI = Child Abuse Potential Inventory, Abuse Scale; ATS = Attitudes Toward Spanking.

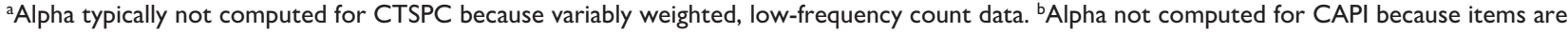
variably weighted.

the CTSPC Physical Assault scale for either Bad or Danger stimuli. However, in the second sample (in which mothers were responding anonymously), mothers' who reported greater parent-child aggression use reported significantly more worry for Bad stimuli and obtained significantly higher hit/spank scores for both Bad and Danger stimuli and lower use of distraction.

Table 5 reports correlations using the longitudinal data available for Sample 1, between APEAR total scores for Bad and Danger stimuli assessed at Time 5 with Time 3 and Time 4 measures of abuse risk (AAPI-2 Total, CAPI Abuse Scale, ReACCT Noncompliance analog task) as well as actual parent-child aggression use (CTSPC Physical Assault). Mothers who reported more anger to either child misbehavior or dangerous behavior on APEAR generally attained higher child abuse risk scores on the AAPI-2 or the ReACCT analog task, although the CAPI Abuse scale was only significantly related with APEAR Bad stimuli, not Danger stimuli. Mothers who reported more worry specifically in response to misbehavior were more likely to attain higher abuse risk on all three measures of abuse risk (AAPI-2 Total, CAPI Abuse Scale, and ReACCT Noncompliance). Mothers who selected Hit/Spank to either misbehavior or dangerous behavior had higher scores on measures of abuse risk (AAPI-2 Total, ReACCT Noncompliance). Mothers who selected Distraction for either misbehavior or dangerous behavior had previously attained lower abuse risk scores on the AAPI-2 abuse risk measure as well as on the CAPI Abuse Scale when their children were 18 months old. Mothers who reported more 
Table 3. Sample I Concurrent Relations of APEAR Bad and Danger Stimuli, Vignettes, Abuse Risk, and Parent-Child Aggression Approval.

\begin{tabular}{|c|c|c|c|c|c|c|c|c|}
\hline & APEAR Anger & APEAR Worry & $\begin{array}{l}\text { APEAR Hit/ } \\
\text { Spank }\end{array}$ & $\begin{array}{l}\text { APEAR } \\
\text { Distract }\end{array}$ & $\begin{array}{l}\text { AAPI-2 } \\
\text { Total }\end{array}$ & $\begin{array}{l}\text { CTSPC } \\
\text { Physical }\end{array}$ & \multicolumn{2}{|c|}{ ATS Total } \\
\hline \multicolumn{9}{|c|}{ APEAR-Bad Stimuli with Abuse Risk and Parent-Child Aggression Approval } \\
\hline APEAR Anger & & & & & $.32 * * *$ & .13 & \multicolumn{2}{|c|}{$.35 * * *$} \\
\hline APEAR Worry & $.34 * * *$ & & & & $.39 * * *$ & .00 & \multicolumn{2}{|c|}{.15} \\
\hline APEAR Hit/Spank & $.36 * * *$ & $.23^{*}$ & & & $.37 * * *$ & .15 & \multicolumn{2}{|c|}{$.32 * * *$} \\
\hline APEAR Distract & $-.33 * * *$ & -.14 & $-.39 * * *$ & & $-.37 * * *$ & -.15 & \multicolumn{2}{|c|}{$-.27 * *$} \\
\hline APEAR Punish & $.33 * * *$ & $.18^{\dagger}$ & $-.22 *$ & $-.44 * * *$ & $.19^{\dagger}$ & .10 & \multicolumn{2}{|c|}{$.27 * *$} \\
\hline \multicolumn{9}{|c|}{ APEAR-Danger Stimuli with Abuse Risk and Parent-Child Aggression Approval } \\
\hline APEAR Anger & & & & & $.46 * * *$ & .03 & \multicolumn{2}{|c|}{.08} \\
\hline APEAR Worry & .02 & & & & $-.20 *$ & -.05 & \multicolumn{2}{|c|}{-.04} \\
\hline APEAR Hit/Spank & $.32 * * *$ & -.04 & & & $.42 * * *$ & .09 & \multicolumn{2}{|c|}{$.26 * *$} \\
\hline APEAR Distract & $-.52 * * *$ & .17 & $-.60 * * *$ & & $-.47 * * *$ & -.07 & \multicolumn{2}{|c|}{-.15} \\
\hline APEAR Punish & $.43 * * *$ & -.06 & .06 & $-.80 * * *$ & $.23 *$ & .03 & \multicolumn{2}{|c|}{.00} \\
\hline \multicolumn{9}{|c|}{ Plotkin Child Vignettes (PCV)_Adapted with APEAR Bad Stimuli, Abuse Risk, and Parent-Child Aggression Approval } \\
\hline & APEAR Anger & APEAR Worry & $\begin{array}{l}\text { APEAR Hit/ } \\
\text { Spank }\end{array}$ & $\begin{array}{l}\text { APEAR } \\
\text { Punish }\end{array}$ & $\begin{array}{l}\text { APEAR } \\
\text { Distract }\end{array}$ & $\begin{array}{l}\text { AAPI-2 } \\
\text { Total }\end{array}$ & $\begin{array}{l}\text { CTSPC } \\
\text { Physical }\end{array}$ & ATS Total \\
\hline PCV Anger & $.32 * * *$ & -.13 & -.01 & $.24 *$ & -.11 & .10 & $.23^{*}$ & $.25^{* *}$ \\
\hline PCV Worry & .05 & $.22 *$ & -.02 & .09 & .03 & -.03 & $.20 *$ & .13 \\
\hline PCV Hit/Spank & $.29 * *$ & .11 & $.53 * * *$ & -.03 & $-.27 * *$ & $.39 * * *$ & $.33 * * *$ & $.32 * * *$ \\
\hline PCV Punish & $.29 * *$ & -.08 & -.06 & $.24 *$ & .06 & -.05 & .05 & .07 \\
\hline PCV Attribution & $.28 * *$ & $.19 *$ & .06 & $.25 * *$ & $-.21 *$ & $.32 * * *$ & $.19 *$ & $.23 *$ \\
\hline
\end{tabular}

Note. APEAR = Automatic Parent Emotion Analog Response task; AAPI-2 = Adult Adolescent Parenting Inventory-2; CTSPC Physical $=$ Parent-Child Conflict Tactics Scale, Physical Assault Subscale; ATS = Attitudes toward Spanking Scale.

$* p \leq .05 . * * p \leq .01 . * * * p \leq .00 \mathrm{I}$. †only marginal at $p \leq .07$.

parent-child aggression use (CTSPC Physical Assault) when their toddlers were 18 months old were modestly more likely to select Hit/Spank for misbehavior 3 or more years later but otherwise, self-reported physical aggression tactics across time were unrelated to APEAR scores.

\section{APEAR Concurrent Validity Evidence}

Tables 3 and 4 also depict correlations of the APEAR Bad and Danger stimuli with the two social-information processing processes, approval of parent-child aggression (ATS Total) and negative child intent attributions (PCV Attribution Total) for the two samples. Mothers who endorse more physical parent-child aggression were more likely to report anger (for both misbehavior and dangerous behavior in the second sample, but only misbehavior in the first sample). Furthermore, mothers with higher approval of parent-child aggression (ATS Total) scores were significantly more likely to choose hit/spank for either Bad or Danger stimuli. Mothers with higher approval of parentchild aggression (ATS Total) were also less likely to use distraction (for both types of stimuli in the second sample but only for misbehavior in the first sample).

Regarding associations with negative child attributions, mothers with higher self-reported PCV Attribution scores were significantly more likely to report anger and worry to APEAR Bad stimuli in both samples. Greater negative child attributions were also associated with more hit/spank selections in Sample 2 (the anonymous sample) but unrelated to hit/spank selections in Sample 1, wherein mothers in the first sample appeared to instead select Punish options.

\section{APEAR Construct Validity Evidence}

Tables 3 and 4 also present the bivariate correlations between conscious processing (PCV) and automatic processing (APEAR Bad stimuli) of misbehavior by sample. For example, the anger, worry, and hit/spank scores for the APEAR Bad stimuli were significantly correlated with the corresponding PCV scores for both samples. For comparison purposes to be thorough, we also provide the bivariate PCV self-report measure correlations with the AAPI-2 abuse risk measure, self-reported parent-child aggression use on the CTSPC Physical Assault subscale, and ATS Total scores of parent-child aggression approval, comparable to those reported for the APEAR Bad stimuli.

Multiple regression analyses regressing both APEAR Bad Hit/Spank and PCV Hit/Spank total scores on abuse risk (using AAPI-2 Total scores) were conducted for both samples. In Sample 1, both independently significantly 
Table 4. Sample 2 Concurrent Relations of APEAR Bad and Danger Stimuli, Vignettes, Abuse Risk, and Parent-Child Aggression Approval.

\begin{tabular}{|c|c|c|c|c|c|c|c|c|}
\hline & $\begin{array}{l}\text { APEAR } \\
\text { Anger }\end{array}$ & $\begin{array}{l}\text { APEAR } \\
\text { Worry }\end{array}$ & $\begin{array}{l}\text { APEAR Hit/ } \\
\text { Spank }\end{array}$ & $\begin{array}{l}\text { APEAR } \\
\text { Distract }\end{array}$ & AAPI-2 Total & $\begin{array}{l}\text { CTSPC } \\
\text { Physical }\end{array}$ & \multicolumn{2}{|c|}{ ATS Total } \\
\hline \multicolumn{9}{|c|}{ APEAR-Bad Stimuli with abuse risk and parent-child aggression approval } \\
\hline APEAR Anger & & & & & $.22 * *$ & .09 & \multicolumn{2}{|c|}{$.16^{*}$} \\
\hline APEAR Worry & $.26 * * *$ & & & & $.37 * * *$ & $.26 * * *$ & \multicolumn{2}{|c|}{$.27 * * *$} \\
\hline APEAR Hit/Spank & $.26 * * *$ & $.30 * * *$ & & & $.47 * * *$ & $.37 * * *$ & \multicolumn{2}{|c|}{$.51 * * *$} \\
\hline APEAR Distract & $-.32 * * *$ & -.02 & $-.28 * * *$ & & $-.35 * * *$ & $-.15^{*}$ & \multicolumn{2}{|c|}{$-.30 * * *$} \\
\hline APEAR Punish & $.46 * * *$ & .04 & $-.14^{*}$ & $-.49 * * *$ & .01 & .08 & \multicolumn{2}{|c|}{.03} \\
\hline \multicolumn{9}{|c|}{ APEAR-Danger Stimuli with abuse risk and parent-child aggression approval } \\
\hline APEAR Anger & & & & & $.43 * * *$ & $.16 *$ & \multicolumn{2}{|c|}{$.31 * * *$} \\
\hline APEAR Worry & .11 & & & & $-.29 * * *$ & $-.14^{\dagger}$ & \multicolumn{2}{|c|}{-.10} \\
\hline APEAR Hit/Spank & $.41 * * *$ & -.02 & & & $.39 * * *$ & $.30 * * *$ & \multicolumn{2}{|c|}{$.42 * * *$} \\
\hline APEAR Distract & $-.56 * * *$ & $.27 * * *$ & $-.61 * * *$ & & $-.47 * * *$ & $-.30 * * *$ & \multicolumn{2}{|c|}{$-.34 * * *$} \\
\hline APEAR Punish & $.49 * * *$ & .09 & .10 & $-.67 * * *$ & $.15^{*}$ & $.14 *$ & \multicolumn{2}{|c|}{.08} \\
\hline \multicolumn{9}{|c|}{ Plotkin Child Vignettes (PCV)_Adapted with APEAR Bad Stimuli, Abuse Risk, and Parent-Child Aggression Approval } \\
\hline & $\begin{array}{l}\text { APEAR } \\
\text { Anger }\end{array}$ & $\begin{array}{l}\text { APEAR } \\
\text { Worry }\end{array}$ & $\begin{array}{l}\text { APEAR Hit/ } \\
\text { Spank }\end{array}$ & $\begin{array}{l}\text { APEAR } \\
\text { Punish }\end{array}$ & $\begin{array}{l}\text { APEAR } \\
\text { Distract }\end{array}$ & $\begin{array}{l}\text { AAPI-2 } \\
\text { Total }\end{array}$ & $\begin{array}{l}\text { CTSPC } \\
\text { Physical }\end{array}$ & $\begin{array}{l}\text { ATS } \\
\text { Total }\end{array}$ \\
\hline PCV Anger & $.48 * * *$ & $.17 *$ & $.27 * * *$ & .10 & -.12 & $.40 * * *$ & $.30 * * *$ & $.24 * * *$ \\
\hline PCV Worry & .09 & $.49 * *$ & .11 & -.01 & .11 & $.29 * * *$ & $.29 * * *$ & $.24 * * *$ \\
\hline PCV Hit/Spank & .09 & $.19 * *$ & $.43 * * *$ & $-.19 * *$ & $-.19 * *$ & $.52 * * *$ & $.50 * * *$ & $.4 I^{* * *}$ \\
\hline PCV Punish & $.23 * *$ & .01 & .01 & $.22 * *$ & $-.20 * *$ & $.16^{*}$ & -.03 & .11 \\
\hline PCV Attribution & .25 & $.22 * *$ & $.29 * * *$ & -.04 & -.11 & $.61 * * *$ & $.32^{* * *}$ & $.27 * * *$ \\
\hline
\end{tabular}

Note. APEAR = Automatic Parent Emotion Analog Response task; AAPI-2 = Adult Adolescent Parenting Inventory-2; CTSPC Physical $=$ Parent-Child Conflict Tactics Scale Physical Assault Subscale; ATS = Attitudes toward Spanking Scale.

${ }^{*} p \leq .05 .{ }^{* *} p \leq .01 .{ }^{* * *} p \leq .00 \mathrm{I}$. ${ }^{\dagger}$ only marginal at $p \leq .07$.

Table 5. Longitudinal Correlations of APEAR Bad and Danger Stimuli With Earlier Abuse Risk Measures.

\begin{tabular}{|c|c|c|c|c|c|c|c|c|c|c|}
\hline & \multicolumn{5}{|c|}{ APEAR-Bad Stimuli } & \multicolumn{5}{|c|}{ APEAR-Danger Stimuli } \\
\hline & Anger & Worry & Hit/Spank & Distract & Punish & Anger & Worry & Hit/Spank & Distract & Punish \\
\hline & $r$ & $r$ & $r$ & $r$ & $r$ & $r$ & $r$ & $r$ & $r$ & $r$ \\
\hline \multicolumn{11}{|l|}{ Time 3} \\
\hline AAPI-2 Total & $.27^{*}$ & $.43 * * *$ & $.36 * * *$ & $-\left..3\right|^{* * *}$ & .09 & $.43 * * *$ & -.15 & $.42 * * *$ & $-.38 * * *$ & .16 \\
\hline CTSPC-Physical & .10 & .00 & $.24^{*}$ & -.03 & .01 & -.09 & .01 & .03 & .07 & -.14 \\
\hline ReACCT Noncomply & .12 & $.28 * *$ & $.47^{* * *}$ & $-.34 * * *$ & -.05 & $.27 * *$ & $-.21^{*}$ & $.4 I^{* * *}$ & $-.31 * *$ & .03 \\
\hline CAPI Abuse Scale & $.23^{*}$ & $.34 * * *$ & .14 & $-.32 * * *$ & .14 & .13 & -.12 & .12 & $-.20^{*}$ & .08 \\
\hline \multicolumn{11}{|l|}{ Time 4} \\
\hline AAPI-2 Total & $.20^{\dagger}$ & $.38 * * *$ & $.31 * *$ & $-.29 * *$ & .12 & $.4 I^{* * *}$ & $-.28 * *$ & $.4 I^{* * *}$ & $-.40 * * *$ & .17 \\
\hline CTSPC Physical & .17 & .09 & .10 & -.01 & .12 & .06 & .00 & .05 & .03 & -.09 \\
\hline ReACCT Noncomply & $.28 * *$ & $.29 * *$ & $.48^{* * *}$ & $-.20^{\dagger}$ & -.08 & $.37 * * *$ & -.15 & $.45 * * *$ & $-.27 * *$ & -.04 \\
\hline CAPI Abuse Scale & $.23^{*}$ & $.42 * * *$ & .09 & $-.20^{\dagger}$ & .14 & .11 & .06 & .11 & -.13 & .08 \\
\hline
\end{tabular}

Note. APEAR = Automatic Parent Emotion Analog Response task; AAPI-2 = Adult Adolescent Parenting Inventory-2; CTSPC Physical = Parent-Child Conflict Tactics Scale, Physical Assault Subscale; ReACCT Noncompliance = Response Analog to Child Compliance Task, Noncompliance Scale; CAPI $=$ Child Abuse Potential Inventory, Abuse Scale.

$* p \leq .05 . * * \leq .01$. ***p $\leq .001$. †only marginal at $p \leq .07$.

predicted AAPI-2 Total: $R^{2}=.19, p \leq .001, \mathrm{PCV} \beta=.27$, $t=2.63, p=.01$, APEAR $\beta=.22, t=2.09, p=.04$. Regressing both APEAR and PCV scores on CTSPC
Physical Assault scores of self-reported parent-child aggression in Sample 1, only the PCV self-report was significant: $R^{2}=.11, p \leq .001, \mathrm{PCV} \beta=.33, t=3.02$, 
Table 6. Multitrait-Multimethod Matrix of Combined Sample APEAR Bad Stimuli and Parent-Child Vignettes.

\begin{tabular}{|c|c|c|c|c|c|c|}
\hline & APEAR Anger & APEAR Worry & APEAR Hit/Spank & PCV Anger & PCV Worry & PCV Hit/Spank \\
\hline APEAR Bad Anger & $(.76)$ & & & & & \\
\hline APEAR Bad Worry & $.30 * * *$ & $(.83)$ & & & & \\
\hline APEAR Bad Hit/Spank & $.30 * * *$ & $.27 * * *$ & $(.76)$ & & & \\
\hline PCV Anger & $.43 * * *$ & .09 & $.17 * *$ & $(.92)$ & & \\
\hline PCV Worry & .11 & $.42 * * *$ & .08 & $.48 * * *$ & $(.91)$ & \\
\hline PCV Hit/Spank & $.15^{*}$ & $.17 * *$ & $.43 * * *$ & $.33 * * *$ & $.22 * * *$ & $(.76)$ \\
\hline
\end{tabular}

Note.. Internal consistency values (alpha) appear in parentheses on the diagonal. Shaded values reflect the monotrait-heteromethod validity diagonal. APEAR = Automatic Parent Emotion Analog Response task; PCV = Plotkin Child Vignettes-Adapted $* p \leq .05 . * * p \leq .01 . * * * p \leq .001$.

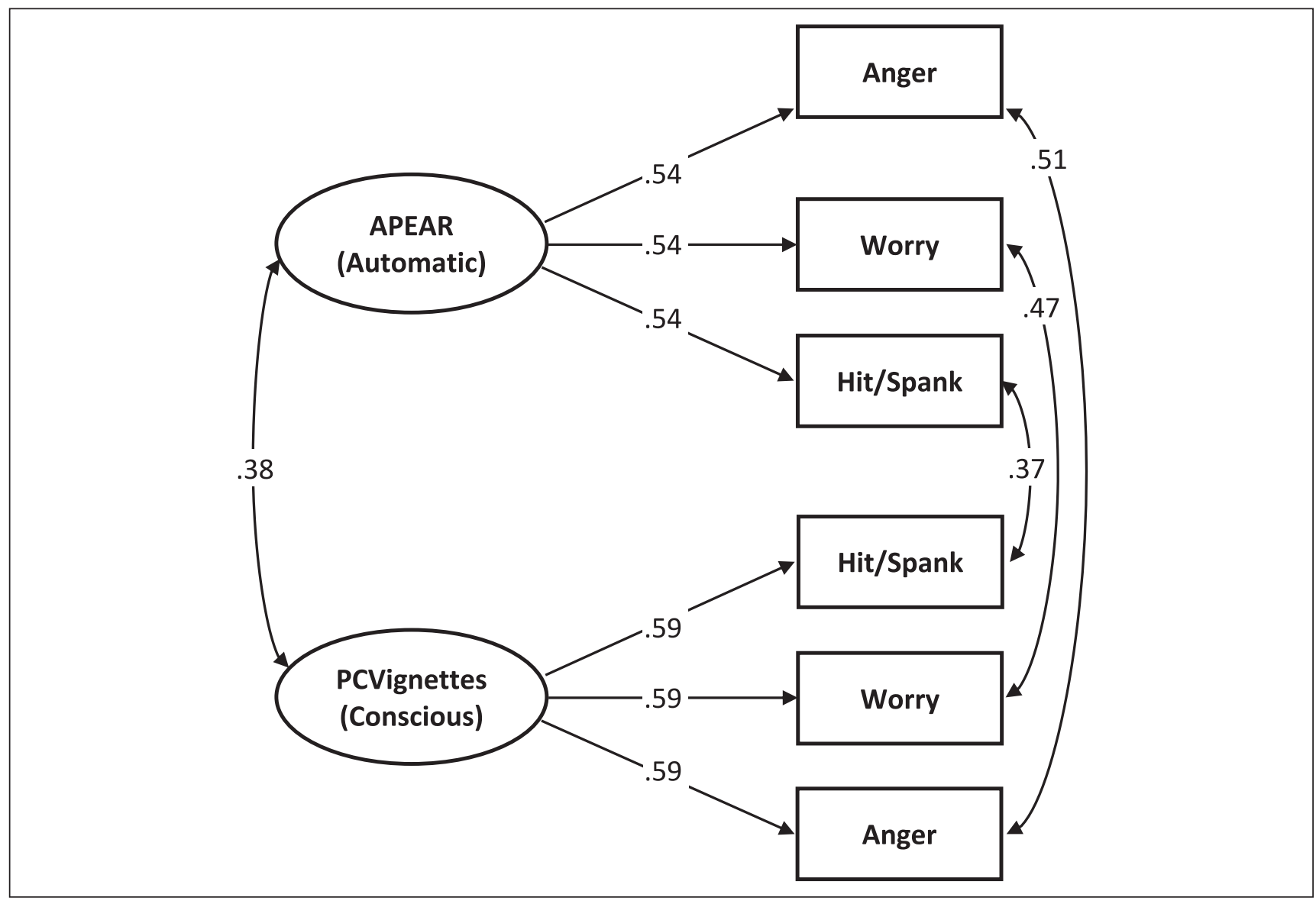

Figure 2. Multitrait multimethod matrix confirmatory factor analysis for automatic and conscious processing. Note. Standardized path coefficients, all $p \leq .00$ I.APEAR = Automatic Parent Emotion Analog Response task; PCVignettes = Plotkin Child Vignettes.

$p=.003$, APEAR $\beta=.00, t=-0.07, p>.05$. In Sample 2 , both again independently significantly predicted AAPI-2 Total abuse risk scores: $R^{2}=.34, p \leq .001, \mathrm{PCV} \beta=.39, t$ $=5.76, p \leq .001$, APEAR $\beta=.28, t=4.22, p \leq .001$. In contrast to the first sample, in Sample 2, both also predicted self-reported parent-child aggression use with CTSPC Physical Assault scores: $R^{2}=.28, p \leq .001$, PCV $\beta=.42$, $t=6.12, p \leq .001$, APEAR $\beta=.20, t=2.87, p=.005$.
Combining both samples, we conducted an MTMM evaluation with APEAR Bad Anger, Worry, and Hit/Spank and their comparable values on the PCV conscious processing vignettes. See Table 6 for the bivariate MTMM correlation matrix, with internal consistencies from the combined sample depicted in the main reliability diagonal. In the validity diagonal (shaded boxes of monotrait-heteromethod values), all three corresponding scores are significantly 
related and provide further evidence of convergent validity. Note these values are also stronger than those values that share either the same trait or the same method (the one exception being the stronger monomethod correlation observed between PCV Anger and Worry), demonstrating evidence of discriminant validity.

Finally, the MTMM was evaluated with a correlateduniqueness CFA in which the methods (APEAR, PCV) predicted their three trait scores (Anger, Worry, and Hit/Spank; see Figure 2). The paths from each method to its respective trait scores were constrained to be equal, and the correlation of the APEAR and PCV method factors was freely estimated. This model demonstrated good fit, $\chi^{2} /$ degrees of freedom $=2.03$, comparative fit index $=.950$, root mean square error of approximation $=.058(90 \%$ CI $[.025, .090])$, standardized root mean square residual $=.044$. Each trait significantly loaded onto their respective method, the two methods were significantly related, and each trait was significantly related between the two methods.

\section{Discussion}

Although parental aggression toward children represents a significant risk for clinical problems (Coley et al., 2014; Font \& Berger, 2015; Maneta et al., 2017; Sousa et al., 2018), several gaps are apparent in the extant research. Parent-child aggression risk research has centered on conscious processing (Milner, 2000), particularly cognitive elements (Azar et al., 2016; Beckerman et al., 2018), and primarily for perceived child misbehavior rather than considering dangerous child behavior (cf. Bower-Russa et al., 2001; Crouch et al., 2017); in the limited instances where emotion is considered, parental anger is emphasized (e.g., Rodriguez, 2018; Smith Slep \& O'Leary, 2007). Therefore, the current investigation explored these gaps using two samples of mothers, evaluating a new automatic processing analog task incorporating mothers' affective reactions of both anger and worry as well as discipline intentions toward both child misbehavior and dangerous behavior, contrasted to responses on a more traditional, conscious processing self-report measure. The APEAR demonstrated acceptable reliability as well as convergent validity (both cross-sectionally and longitudinally), concurrent validity, and construct validity.

As evidence of convergent validity, across both samples, mothers who automatically selected physical discipline responses to either misbehavior or dangerous behavior were more likely to obtain higher child abuse risk scores. We observed similar associations for the first sample regarding increased automatic selections of hit/spank responses and their higher abuse risk scores from earlier assessments using the longitudinal data. However, only in the second sample did we observe that mothers' inclination to automatically choose hit responses related to their self-report of using parent-child aggression in the home (notwithstanding that this relation was observed in the longitudinal findings wherein mothers' who reported greater parent-child aggression use several years earlier - the first time they were reporting on parent-child aggression behavior explicitlywere more likely to automatically select hit responses for misbehavior). Because the measure of parent-child aggression use is highly explicit (Straus et al., 1998), and thus vulnerable to well-recognized underreporting biases (Chan, 2012; Meinck et al., 2016), this discrepancy between samples is provocative. Mothers in the second sample were responding anonymously, whereas those in the first sample have been known to our lab for several years. Together, these findings expose the continuing challenges posed to those working in the field of child abuse and parent-child aggression of relying on parents' willingness to self-disclose their utilization of parent-child aggression nonanonymously.

The APEAR analog task also demonstrated concurrent validity with social-information processing elements of parent-child aggression approval and negative child intent attributions. Mothers who reported anger at child misbehavior and automatically selected hit responses to either child misbehavior or dangerous behavior were more likely to endorse parent-child aggression as an acceptable discipline approach, mirroring previously observed links between this social-information processing preexisting schema and child abuse risk (Bi \& Keller, 2019; Coley et al., 2014). Mothers who reported they experienced more anger when observing child misbehavior and who chose more physical discipline responses were also more likely to ascribe negative intent to children's behavior. Such negative child intent attributions are considered an indicator of social-information processing negative interpretations (Milner, 2000) which are associated with and predict parent-child aggression risk (Azar et al., 2016; Camilo et al., 2020; Rodriguez et al., 2019, 2020). Thus, the APEAR task performed consistent with the premises of social-information processing theory.

The APEAR analog task also demonstrated construct validity, with mothers' anger, worry, and physical discipline selections on the APEAR task paralleling those on the conscious processing self-report measure, conveying additional convergent validity. Regression analyses confirmed that physical discipline selections on both the automatic and conscious processing measures were independently related to child abuse risk in both samples (AAPI-2 Total) and to self-reported parent-child aggression use (CTSPC) in the second sample. Because mothers in the second sample were responding anonymously, the regression finding that automatic and conscious processing independently related to reported parent-child aggression use in the home may be more robust relative to the first sample. In support of that interpretation, the analyses of the MTMM confirmed convergence across traits while also indicating automatic and 
conscious processing were distinct. As theorized in dualprocessing models of aggression (Bluemke \& TeigeMocigemba, 2015), conscious and automatic processes may lead to behavioral enactment of parent-child aggression along parallel routes. Given the differences in findings with regard to self-reported parent-child aggression use in the home between samples, continued research should investigate whether both automatic and conscious processing indeed lead parents to engage in aggressive responding, although the current preliminary findings suggest this may be the case.

Our findings further support that both maternal anger and maternal worry are important affective elements to explore, specifically for perceived child misbehavior. Despite the current emphasis on anger (Altafim \& Linhares, 2016; Smith Slep \& O'Leary, 2007), mothers' worry reactions were at least as strong, and sometimes more strongly, related to child abuse risk as anger reactions - an effect evident in both automatic and conscious processing. Although parental anxiety has been recognized as a predictor of child abuse and severe discipline (Pinderhughes et al., 2000; Stith et al., 2009), this affective reaction has been relatively neglected in both clinical and research circles alike, suggesting that both emotions warrant more research inquiry.

Additionally, maternal responses on the new automatic processing analog task demonstrated that those who experienced anger were likely to select physical discipline in response to either perceived child misbehavior or dangerous behavior. Mothers who responded with anger - but not worry-to either misbehavior or dangerous behavior attained higher child abuse risk scores, pointing to a potential distinction in the role of worry in the automatic processing of these two types of child behavior. Child misbehavior has served as the central target for most researchers and clinicians, with few having considered dangerous child behavior in prior research (Bower-Russa et al., 2001; Crouch et al., 2017). Dangerous child behavior thus appears to also need more attention.

Although the current investigation of the APEAR drew from two samples of mothers, included longitudinal data, compared to multiple measures, and provided evidence of different validity properties, a number of limitations are notable. Additional psychometric evidence for the APEAR would appraise test-retest reliability in automatic processing; although the longitudinal results suggest some consistency across large periods of time, future work could evaluate the extent to which parents' automatic affective responses and discipline selections remain stable.

The current analyses engaged mothers to minimize the likelihood of parent gender confounding the results, but future research should evaluate fathers, considering the range of gaps identified earlier regarding processes, emotions, and types of child behavior. Larger sample sizes could permit an examination of subgroup differences in automatic processing, such as mother-father comparisons, but also potential racial/ethnic differences, particularly because our sample underrepresents those identifying as Latina or Asian. Because of the discrepancies observed between samples, replication with other anonymous samples would be particularly enlightening. However, realistically, many researchers (or clinicians) cannot offer anonymity when participants or clients are being followed across time. The field awaits a creative mechanism for gauging parents' actual use of parent-child aggression in the home that does not rely on the underreporting of any parent-child aggression (Chan, 2012; Meinck et al., 2016; Widom et al., 2015) or resort to the underreporting of physical abuse (Sedlak et al., 2010; Stoltenborgh et al., 2015). Although those substantiated for child abuse may represent an atypical fraction of those who engage in abuse, it would nonetheless provide additional validity evidence to ascertain whether automatic processing for such a sample reveals more frequent experience of anger or worry and inclination to select hit responses compared with their nonabusive peers.

Overall, the current investigation provides initial psychometric support for the APEAR automatic processing analog task in terms of reliability and validity with two independent samples of mothers. Additionally, these findings suggest the need to consider both anger and worry and both misbehavior and dangerous behavior, and offers preliminary support for a dual processing model applicable to parent-child aggression. One out of every eight children will be officially identified as victims of child maltreatment by age 18 years (Wildeman et al., 2014), which remains an underestimate of its true extent (Meinck et al., 2016; Sedlak et al., 2010; Stoltenborgh et al., 2015). Thus, greater strides in comprehensive, accurate assessment of the causal mechanisms are needed urgently and dual-processing models may better capture the routes that may prompt a parent to engage in parent-child aggression.

\section{Authors' Note}

The content is solely the responsibility of the authors and does not necessarily represent the official views of the National Institute of Child Health and Human Development or the National Institutes of Health.

\section{Acknowledgments}

We thank our participating families and participating Obstetrics/ Gynecology clinics that facilitated recruitment.

\section{Declaration of Conflicting Interests}

The author(s) declared no potential conflicts of interest with respect to the research, authorship, and/or publication of this article. 


\section{Funding}

The author(s) disclosed receipt of the following financial support for the research, authorship, and/or publication of this article: This research was supported by award number R15HD071431 from the National Institute of Child Health and Human Development to the first author.

\section{ORCID iD}

Christina M. Rodriguez https://orcid.org/0000-0002-5090-0707

\section{References}

Afifi, T. O., Mota, N., Sareen, J., \& MacMillan, H. L. (2017). The relationships between harsh physical punishment and child maltreatment in childhood and intimate partner violence in adulthood. BMC Public Health, 17, Article 493. https://doi. org/10.1186/s12889-017-4359-8

Altafim, E. R. P., \& Linhares, M. B. M. (2016). Universal violence and child maltreatment prevention programs for parents: A systematic review. Psychosocial Intervention, 25(1), 27-38. https://doi.org/10.1016/j.psi.2015.10.003

Ateah, C. A., \& Durrant, J. E. (2005). Maternal use of physical punishment in response to child misbehavior: Implications for child abuse prevention. Child Abuse \& Neglect, 29(2), 169-185. https://doi.org/10.1016/j.chiabu.2004.10.010

Averill, J. R. (1982). Anger and aggression: An essay on emotion. Springer-Verlag.

Azar, S. T., Miller, E. A., McGuier, D. J., Stevenson, M. T., O’Donnell, E., Olsen, N., \& Spence, N. (2016). Maternal social information processing and the frequency and severity of mother-perpetrated physical abuse. Child Maltreatment, 21(4), 308-316. https://doi.org/10.1177/1077559516668047

Bavolek, S. J., \& Keene, R. G. (2001). Adult-Adolescent Parenting Inventory (AAPI-2): Administration and development handbook. Family Development Resources, Inc.

Beckerman, M., van Berkel, S. R., Mesman, J., \& Alink, L. R. A. (2018). Negative parental attributions mediate associations between risk factors and dysfunctional parenting: A replication and extension. Child Abuse \& Neglect, 81(July), 249-258. https://doi.org/10.1016/j.chiabu.2018.05.001

Bi, S., \& Keller, P. S. (2019). Parental empathy, aggressive parenting, and child adjustment in a noncustodial high-risk sample. Journal of Interpersonal Violence. Advance online publication. https://doi.org/10.1177/0886260519870165

Bluemke, M., \& Teige-Mocigemba, S. (2015). Automatic processes in aggression: Conceptual and assessment issues. Aggressive Behavior, 41(1), 44-50. https://doi.org/10.1002/ ab. 21576

Bower-Russa, M. E., Knutson, J. F., \& Winebarger, A. (2001). Disciplinary history, adult disciplinary attitudes, and risk for abusive parenting. Journal of Community Psychology, 29(3), 219-240. https://doi.org/10.1002/jcop.1015

Bushman, B. J., \& Anderson, C. A. (2001). Is it time to pull the plug on hostile versus instrumental aggression dichotomy? Psychological Review, 108(1), 273-279. https://doi. org/10.1037/0033-295X.108.1.273

Buss, A. H. (1961). The psychology of aggression. Wiley.
Camilo, C., Vaz Garrido, M., \& Calheiros, M. M. (2016). Implicit measures of child abuse and neglect: A systematic review. Aggression and Violent Behavior, 29(July-August), 43-54. https://doi.org/10.1016/j.avb.2016.06.002

Camilo, C., Vaz Garrido, M., \& Calheiros, M. M. (2020). The social information processing model in child physical abuse and neglect: A meta-analytic review. Child Abuse \& Neglect, 108(October), Article 104666. https://doi.org/10.1016/j. chiabu.2020.104666

Campbell, D. T., \& Fiske, D. W. (1959). Convergent and discriminant validation by the multitrait-multimethod matrix. Psychological Bulletin, 56(2), 81-105. https://doi. org/10.1037/h0046016

Chaffin, M., Bard, D., Hecht, D., \& Silovsky, J. (2011). Change trajectories during home-based services with chronic child welfare cases. Child Maltreatment, 16(2), 114-125. https:// doi.org/10.1177/1077559511402048

Chaffin, M., \& Valle, L. (2003). Dynamic prediction characteristics of the Child Abuse Potential Inventory. Child Abuse \& Neglect, 27(5), 463-481. https://doi.org/10.1016/S01452134(03)00036-X

Chan, K. L. (2012). Comparison of parent and child reports on child maltreatment in a representative household sample in Hong Kong. Journal of Family Violence, 27(1), 11-21. https:// doi.org/10.1007/s10896-011-9405-1

Coley, R. L., Kull, M. A., \& Carrano, J. (2014). Parental endorsement of spanking and children's internalizing and externalizing problems in African American and Hispanic families. Journal of Family Psychology, 28(1), 22-31. https://doi. org/10.1037/a0035272

Compier-de Block, L. H. C., Alink, L. R. A., Reijman, S., Werner, C. D., Maras, A., Rijnberk, C., van IJzendoorn, M. H., \& Bakermans-Kranenburg, M. J. (2015). Handgrip force of maltreating mothers in reaction to infant signals. Child Abuse \& Neglect, 40(February), 124-131. https://doi.org/10.1016/j. chiabu.2014.03.006

Conners, N. A., Whiteside-Mansell, L., Deere, D., Ledet, T., \& Edwards, M. C. (2006). Measuring the potential for maltreatment: The reliability and validity of the Adult Adolescent Parenting Inventory-2. Child Abuse \& Neglect, 30(1), 39-53. https://doi.org/10.1016/j.chiabu.2005.08.011

Crouch, J. L., Irwin, L. M., Milner, J. S., Skowronski, J. J., Rutledge, E., \& Davila, A. L. (2017). Do hostile attributions and negative affect explain the association between authoritarian beliefs and harsh parenting? Child Abuse \& Neglect, 67(May), 13-21. https://doi.org/10.1016/j.chiabu.2017.02.019

Crouch, J. L., Irwin, L. M., Wells, B. M., Shelton, C. R., Skowronski, J. J., \& Milner, J. S. (2012). The Word Game: An innovative strategy for assessing implicit processes in parents at risk for child physical abuse. Child Abuse \& Neglect, 36(6), 498-509. https://doi.org/10.1016/j.chiabu.2012.04.004

Duffy, J. Y., Hughes, M., Asnes, A. G., \& Leventhal, J. M. (2015). Child maltreatment and risk patterns among participants in a child abuse prevention program. Child Abuse \& Neglect, 44(June), 184-193. https://doi.org/10.1016/j. chiabu.2014.11.005

Durrant, J. E., Trocmé, N., Fallon, B., Milne, C., \& Black, T. (2009). Protection of children from physical maltreatment 
in Canada: An evaluation of the Supreme Court's definition. Journal of Aggression, Maltreatment \& Trauma, 18(1), 6487. https://doi.org/10.1080/10926770802610640

Farc, M. M., Crouch, J. L., Skowronski, J. J., \& Milner, J. S. (2008). Hostility ratings by parents at risk for child abuse: Impact of chronic and temporary schema activation. Child Abuse \& Neglect, 32(2), 177-193. https://doi.org/10.1016/j. chiabu.2007.06.001

Fazio, R. H., \& Olson, M. A. (2003). Implicit measures in social cognition research: Their meaning and use. Annual Review of Psychology, 54, 297-327. https://doi.org/10.1146/annurev. psych.54.101601.145225

Font, S. A., \& Berger, L. M. (2015). Child maltreatment and children's developmental trajectories in early to middle childhood. Child Development, 86(2), 536-556. https://doi. org/10.1111/cdev.12322

Gershoff, E. T. (2010). More harm than good: A summary of the scientific research on the intended and unintended effects of corporal punishment on children. Law and Contemporary Problems, 73(2), 31-56. https://www.jstor.org/stable/25766386

Gershoff, E. T., \& Grogan-Kaylor, A. (2016). Spanking and child outcomes: Old controversies and new meta-analyses. Journal of Family Psychology, 30(4), 453-469. https://doi. org/10.1037/fam0000191

Gonzalez, M., Durrant, J. E., Chabot, M., Trocmé, N., \& Brown, J. (2008). What predicts injury from physical punishment? A test of the typologies of violence hypothesis. Child Abuse \& Neglect, 32(8), 752-765. https://doi.org/10.1016/j. chiabu.2007.12.005

Haskett, M. E., Scott, S. S., Willoughby, M., Ahern, L., \& Nears, K. (2006). The Parent Opinion Questionnaire and child vignettes for use with abusive parents: Assessment of psychometric properties. Journal of Family Violence, 21(2), 137151. https://doi.org/10.1007/s10896-005-9010-2

Hien, D., Cohen, L. R., Caldeira, N. A., Flom, P., \& Wasserman, G. (2010). Depression and anger as risk factors underlying the relationship between substance involvement and child abuse potential. Child Abuse \& Neglect, 34(2), 105-111. https://doi. org/10.1016/j.chiabu.2009.05.006

Holden, G. W. (2001). Attitude toward spanking (ATS). In J. Touliatos, B. F. Perlmutter, \& G. W. Holden (Eds.), Abstracts: Vol. 2. Handbook of family measurement techniques (p. 209). Sage.

Kline, R. B. (2011). Principles and practice of structural equation modeling. Guilford Press.

Lemerise, E. A., \& Arsenio, W. F. (2000). An integrated model of emotion process and cognition in social information processing. Child Development, 71(1), 107-118. https://doi. org/10.1111/1467-8624.00124

Maneta, E. K., White, M., \& Mezzacappa, E. (2017). Parent-child aggression, adult-partner violence, and child outcomes: A prospective, population-based study. Child Abuse \& Neglect, 68(June), 1-10. https://doi.org/10.1016/j.chiabu.2017.03.017

McElroy, E., \& Rodriguez, C. M. (2008). Mothers of children with externalizing behavior problems: Cognitive risk factors for abuse potential and discipline style and practices. Child Abuse \& Neglect, 32(8), 774-784. https://doi.org/10.1016/j. chiabu.2008.01.002
Meinck, F., Steinert, J. I., Sethi, D., Gilbert, R., Bellis, M. A., Mikton, C., Alink, L., \& Baban, A. (2016). Measuring and monitoring national prevalence of child maltreatment: A practical handbook. World Health Organization.

Milner, J. S. (1986). The Child Abuse Potential Inventory: Manual (2nd ed.). Psyctec.

Milner, J. S. (1994). Assessing physical child abuse risk: The Child Abuse Potential Inventory. Clinical Psychology Review, 14(6), 547-583. https://doi.org/10.1016/0272-7358 (94)90017-5

Milner, J. S. (2000). Social information processing and child physical abuse: Theory and research. In D. J. Hansen (Ed.), Nebraska symposium on motivation, Vol. 46, 1998: Motivation and child maltreatment (pp. 39-84). University of Nebraska Press.

Orobio de Castro, B. O. (2004). The development of social information processing and aggressive behaviour: Current issues. European Journal of Developmental Psychology, 1(1), 87102. https://doi.org/10.1080/17405620444000058

Palan, S., \& Schitter, C. (2018). Prolific.ac: A subject pool for online experiments. Journal of Behavioral and Experimental Finance, 17(March), 22-27. https://doi.org/10.1016/j. jbef.2017.12.004

Pinderhughes, E. E., Dodge, K. A., Bates, J. E., Pettit, G. S., \& Zelli, A. (2000). Discipline responses: Influences of parents' socioeconomic status, ethnicity, beliefs about parenting, stress, and cognitive-emotional processes. Journal of Family Psychology, 14(3), 380-400. https://doi.org/10.1037/08933200.14.3.380

Plotkin, R. (1983). Cognitive mediation in disciplinary actions among mothers who have abused or neglected their children: Dispositional and environmental factors [Unpublished doctoral dissertation]. University of Rochester.

Rabbit, S., \& Rodriguez, C. M. (2019). Assessing parental attributions through an implicit measure: Development and evaluation of the Noncompliance IAT. Journal of Child and Family Studies, 28(4), 894-905. https://doi.org/10.1007/s10826-01801315-2

Robitzsch, A., Kiefer, T., \& Wu, M. (2020). TAM: Test Analysis Modules (R package version 3.5.19). https://CRAN.R-project. org $/$ package $=$ TAM

Rodriguez, C. M. (2006). Attributional style as a mediator between parental abuse risk and child internalizing symptomatology. Child Maltreatment, 11(2), 121-130. https://doi. org/10.1177/1077559505285743

Rodriguez, C. M. (2010). Parent-child aggression: Association with child abuse potential and parenting styles. Violence and Victims, 25(6), 728-741. https://doi.org/10.1891/08866708.25.6.728

Rodriguez, C. M. (2016). Parental discipline reactions to child noncompliance and compliance: Association with parentchild aggression indicators. Journal of Child and Family Studies, 25(4), 1363-1374. https://doi.org/10.1007/s10826015-0308-2

Rodriguez, C. M. (2018). Predicting parent-child aggression risk: Cognitive factors and their interaction with anger. Journal of Interpersonal Violence, 33(3), 359-378. https://doi. org/10.1177/0886260516629386 
Rodriguez, C. M., Bower Russa, M., \& Harmon, N. (2011). Assessing abuse risk beyond self-report: Analog task of acceptability of parent-child aggression. Child Abuse \& Neglect, 35(3), 199-209. https://doi.org/10.1016/j.chiabu.2010.12.004

Rodriguez, C. M., Cook, A. E., \& Jedrziewski, C. T. (2012). Reading between the lines: Implicit assessment of the association of parental attributions and empathy with abuse risk. Child Abuse \& Neglect, 36(7-8), 564-571. https://doi. org/10.1016/j.chiabu.2012.05.004

Rodriguez, C. M., \& Richardson, M. J. (2007). Stress and anger as contextual factors and pre-existing cognitive schemas: Predicting parental child maltreatment risk. Child Maltreatment, 12(4), 325-337. https://doi.org/10.1177/1077 559507305993

Rodriguez, C. M., Russa, M. B., \& Kircher, J. C. (2015). Analog assessment of frustration tolerance: Association with selfreported child abuse risk and physiological reactivity. Child Abuse \& Neglect, 46(August), 121-131. https://doi. org/10.1016/j.chiabu.2015.02.017

Rodriguez, C. M., Silvia, P. J., \& Gaskin, R. E. (2019). Predicting maternal and paternal parent-child aggression risk: Longitudinal multimethod investigation using social information processing theory. Psychology of Violence, 9(3), 370-382. https://doi.org/10.1037/vio0000115

Rodriguez, C. M., Smith, T. L., \& Silvia, P. J. (2016). Parent-child aggression risk in expectant mothers and fathers: A multimethod theoretical approach. Journal of Child and Family Studies, 25(11), 3220-3235. https://doi.org/10.1007/s10826016-0481-y

Rodriguez, C. M. Wittig, S.M.O., \& Silvia, P.J. (2020). Refining social-information processing theory: Predicting maternal and paternal parent-child aggression risk longitudinally. Child Abuse \& Neglect, 107, 104563. https://doi.org/10.1016/j. chiabu.2020.104563

Russa, M. B., Rodriguez, C. M., \& Silvia, P. J. (2014). Frustration influences impact of history and disciplinary attitudes on physical discipline decision making. Aggressive Behavior, 40(1), 1-11. https://doi.org/10.1002/ab.21500

Sanders, M. R., Pigeon, A. M., Gravestock, F., Connors, M. D., Brown, S., \& Young, R. W. (2004). Does parental attributional retraining and anger management enhance the effects of the Triple-P-Positive Parenting Program with parents at risk of child maltreatment. Behavior Therapy, 35(3), 513-535. https://doi.org/10.1016/S0005-7894(04)80030-3

Sedlak, A. J., Mettenburg, J., Basena, M., Petta, I., McPherson, K., Greene, A., \& Li, S. (2010). Fourth National Incidence Study of Child Abuse and Neglect (NIS-4): Report to Congress, executive summary. U.S. Department of Health \& Human Services. https://www.acf.hhs.gov/media/8885
Smith Slep, A. M., \& O'Leary, S. G. (2007). Multivariate models of mothers' and fathers' aggression toward their children. Journal of Consulting and Clinical Psychology, 75(5), 739751. https://doi.org/10.1037/0022-006X.75.5.739

Sousa, C., Mason, W. A., Herrenkohl, T. I., Prince, D., Herrenkohl, R. C., \& Russo, M. J. (2018). Direct and indirect effects of child abuse and environmental stress: A lifecourse perspective on adversity and depressive symptoms. American Journal of Orthopsychiatry, 88(2), 180-188. https://doi.org/10.1037/ ort0000283

Stith, S. M., Liu, T., Davies, C., Boykin, E. L., Alder, M. C., Harris, J. M., Som, A., McPherson, M., \& Dees, J. E. M. E. G. (2009). Risk factors in child maltreatment: A meta-analytic review of the literature. Aggression and Violent Behavior, 14(1), 13-29. https://doi.org/10.1016/j.avb.2006.03.006

Stoltenborgh, M., Bakermans-Kranenburg, M. J., Alink, L. R. A., \& van IJzendoorn, M. H. (2015). The prevalence of child maltreatment across the globe: Review of a series of metaanalyses. Child Abuse Review, 24(1), 37-50. https://doi. org/10.1002/car.2353

Straus, M. A., Hamby, S. L., Finkelhor, D., Moore, D. W., \& Runyan, D. (1998). Identification of child maltreatment with the Parent-Child Conflict Tactics Scales: Development and psychometric data for a national sample of American parents. Child Abuse \& Neglect, 22(4), 249-270. https://doi. org/10.1016/S0145-2134(97)00174-9

Sturge-Apple, M. L., Rogge, R. D., Peltz, J. S., Suor, J. H., \& Skibo, M. A. (2015). Delving beyond conscious attitudes: Validation of an innovative tool for assessing parental implicit attitudes toward physical punishment. Infant and Child Development, 24(3), 240-255. https://doi.org/10.1002/ icd.1903

U.S. Department of Health \& Human Services. (2020). Child maltreatment 2018. https://www.acf.hhs.gov/cb/resource/childmaltreatment-2018

Widom, C. S., Czaja, S. J., \& DuMont, K. A. (2015). Intergenerational transmission of child abuse and neglect: Real or detection bias? Science, 347(6229), 1480-1485. https://doi. org/10.1126/science. 1259917

Wildeman, C., Emanuel, N., Leventhal, J. M., Putnam-Hornstein, E., Waldfogel, J., \& Lee, H. (2014). The prevalence of confirmed maltreatment among U.S. children, 2004-2011. JAMA Pediatrics, 168(8), 706-713. https://doi.org/10.1001/jamapediatrics.2014.410

Zolotor, A. J., Theodore, A. D., Chang, J. J., Berkoff, M. C., \& Runyan, D. K. (2008). Speak softly-and forget the stick: Corporal punishment and child physical abuse. American Journal of Preventative Medicine, 35(4), 364-369. https://doi. org/10.1016/j.amepre.2008.06.031 